\title{
Study on the Standardization of University Students ' Volunteer Service System
}

\author{
Chao Wang ${ }^{1, a}$ and Yan Song ${ }^{2, b^{*}}$ \\ ${ }^{1,2}$ Xincheng Street 2888, Jilin Agricultural University, Changchun, Jilin Province 130118, PR China \\ a29251275@qq.com \\ * The corresponding author
}

Keywords: University student Volunteer Service; Standardization

\begin{abstract}
The university student volunteer service is the modern society civilization progress important symbol. College students ' volunteer service gives students more opportunities to devote their love to the society and make contribution to the best of their ability. The development of university Students ' volunteer service is beneficial to the healthy growth of college students and the maintenance of social stability. Therefore, it is of practical significance to further strengthen the standardization of the work system of college students ' volunteer service.This paper discusses some suggestions on standardizing the work system of college students ' volunteer service.
\end{abstract}

\section{Concepts Related to Volunteerism}

The Meaning of Voluntary Service. Voluntary service is the product of the development of human civilization to a certain stage, refers to any person who voluntarily contributes their personal time and energy to provide services for the advancement of human development, social progress and social welfare without being materially compensated. The main body of volunteer service is volunteer and volunteer organization. Voluntary service is an indispensable part of every civilized society, in today's world, voluntary service has become a social practice to affect the global service activities.

The Meaning of University Students ' Voluntary Service. The volunteer service is mainly organized by the Communist Youth League organization, in order to take part in the volunteer action of the students, this practice is a kind of practical action that college students take their time, energy and skill to make use of their spare time to voluntary, not to pay for material and income. The university student volunteer service is the time and the social development product, has the distinct characteristic of the times, is the university student participates in the social activity important way, is also the voluntary service enterprise one kind of positive main promotion strength

\section{Characteristics of Volunteerism}

Voluntary Participation of Volunteers. Volunteer service is voluntary and free from the domination of others.

Free of Volunteer Service. Voluntary service is free of charge. Volunteers devote their time, energy and physical energy to the clients without any material remuneration. The essence of voluntary service behavior is to devote society and serve society.

Organizational Rigor Voluntary Service. Voluntary service activities from the recruitment of volunteers, training to organize, development, which are in the system norms and constraints in an orderly manner is an organized mode of activity

\section{The Necessity of College Students ' Volunteering Service}

The Need of Harmonious Campus and Harmonious Society. The university four years is the shaping student personality, is key period of the student setting up the correct outlook on life, the value and the world outlook. In the process of actively participating in voluntary service, college students gradually cultivate values consistent with the social process. Under the guidance of the 
correct values, college students can actively correct their own behavior in the error, with higher standards of strict demands on themselves.

This is the promotion factor of harmonious campus construction. One of the hallmarks of the civilization of modern society is the organization of a large number of public welfare and voluntary service activities. In the activities, selfless dedication, care for others, to help others the spirit has been inherited and carried forward, positive energy has been transferred, China's excellent tradition has been inherited and carried forward. This is compatible with the need for the development and progress of a harmonious society.

The Need to Realize the Goal of Moral Education in Colleges and Universities. The goal of moral education is to cultivate a new person who has the spirit of dedication and lofty ideals for the country and society, which accords with the purpose of the voluntary service activities. College students use their spare time to participate in a variety of voluntary service activities.Students not only increase the experience of social life, but also, in the process, setting up a correct and firm values, improving the moral culture.

The Need to Promote Volunteerism and the Dissemination of Advanced Culture. The aim of university education is "to impart advanced scientific and cultural knowledge, to carry forward the spirit of solidarity, friendship and mutual assistance", and voluntary service is an important way to realize the aim of university education. Through these activities, the gradual exercise of college students has become the successor and disseminator of volunteerism and advanced culture. When college students step into society, they also unconsciously infect social groups, bringing positive energy to others and promoting the construction of social and spiritual civilization

\section{The Significance of College Students ' Volunteering Service}

Help to Improve College Students ' Comprehensive Quality. In the process of promoting the college students ' comprehensive quality volunteering service, they can cultivate the organization and coordination ability,

communication ability and teamwork ability of the volunteers. College students take the initiative to assume a responsibility, but also to cultivate the sense of responsibility and mission.

Help College Students Adapt to Society Faster. It is the process of participation in social practice that helps college students to adapt to the participation of college students in voluntary service more quickly. This is a two-way communication process. Students to provide services to society, but also began to understand the community. This process is conducive to the transformation of college students to qualified professional people.

Promote the Construction of Spiritual Civilization in Colleges. The volunteers are all in various activities with good image and high level of service. Voluntary service activities are beneficial to improve the comprehensive quality of college students. The cultivation of college students ' comprehensive ability is an important part of the construction of spiritual civilization in colleges and universities.

Conducive to Leade the New Fashion of Civilized Life. In the University Student Volunteer Service activity, the university student volunteers can feel the mood to be joyful when helping the service object to solve the problem. In the process of communication between college students ' volunteers and their clients, they also cultivate their friendship. Life began to become less boring, but full of fun to help others. At the same time, college students volunteer to a certain extent to achieve their own life value. College students ' volunteering service accords with the spiritual pursuit of a new generation of young people. "Everybody participates in the volunteer service, everybody enjoys the voluntary service", will become a new social life Vogue. This is a civilized concept of life, is a healthy, positive lifestyle 


\section{The Development Direction of the Standardization of the Volunteer Service System}

University students the content of the volunteer service of the university students is diversified, which pervades all aspects of social life. The system of college students ' volunteer service needs to be standardized

Socialist Core Values Guide the General Direction of College Students ' Voluntary Service. Advocating the socialist core values of "prosperity, democracy, civilization, harmony, freedom, equality, justice, the rule of law, patriotism, devotion, honesty and friendliness", which highlight the three levels of value goals of the country, society and individuals. College students ' volunteering service accords with the socialist core values. In the voluntary service activities, we have practiced the socialist values, stimulated the students ' patriotic feelings, promoted the students ' moral cultivation, carried forward the social mainstream values and promoted the social progress

Identify the Development Goals of Volunteering Services. In the process of constructing the volunteer service system, colleges and universities should first clarify the development goal of their service work. So that the development of the work can better provide services to the community. At the same time, it can also play the professional expertise of students to apply. To improve students ' professional quality and promote their healthy growth

Perfecting the System of Voluntary Service Protection. Perfecting the legal safeguard mechanism. China still does not have a nationwide voluntary service guarantee law, the lack of law often brings an opportunity for outlaws. In addition, college students ' social experience is still lacking. Therefore, in the process of college students ' volunteering service, some serious problems are encountered, sometimes they are not solved in time and properly. The injury of the volunteer's rights and interests will seriously affect the volunteer's enthusiasm for participating in the service.Actively communicate with the government and relevant departments, strengthen the legislative guidance of voluntary service, make sure to do the law, enforced, which can promote the development of college students volunteer service faster.

Establish a funding guarantee mechanism. Voluntary service organizations often face problems of insufficient funds, which affect the development of activities. Actively communicate with local government and charitable organizations, set up a special fund for voluntary service to ensure a stable source of funds. In addition to government funding, the new channels for raising funds can be funded through corporate sponsorship, social fund-raising and other means to ensure adequate funding

Establishment of a Daily Management Mechanism for Voluntary Services. The daily work of university volunteer service includes the selection of volunteers, training, activities planning and development, service promotion and so on. To establish a specialized agency for the daily management of volunteer service, to enhance the importance of the leading departments in the work of volunteer service. We should establish and improve the relevant rules and regulations of voluntary service, strengthen the management of voluntary service, and guarantee the smooth development of voluntary service activities in policy. Colleges are encouraged to set up voluntary service associations to promote the development of voluntary services. While focusing on the needs of the project, more attention should be paid to the individual wishes and satisfaction of volunteers

Establishing Incentive Mechanism for Voluntary Service. Taking various incentive ways to give material rewards and spiritual recognition to outstanding individuals and excellent groups. The establishment of voluntary service files, all participating in voluntary service activities of college students are unified registration. These students are given priority to join the party and apply for scholarships. In the case of employment, the employing unit may be given preferential employment under the same conditions. And the use of campus radio,campus micro-trust public platform to promote, to form a model effect, expand influence. Let good people play a role model in the students, leading more students to participate actively in the activities

Establishment of a Rigorous Training Mechanism. Most college volunteers lack daily training. Only when there is activity, volunteers are recruited temporarily, and simple surprise training is carried out. In order to improve the quality of service and ensure the safety of the volunteers, the volunteers should be trained regularly and the training will be recorded into the volunteer files. The 
training mainly includes the service skill, the communication skill, the team cooperation, the security protection and so on many aspects

Setting up Scientific Voluntary Service. The work of college students ' volunteer service must keep pace with the times and must be updated with the development of the time. According to the learning characteristics of different grades and different majors, and the specific requirements of society to volunteer service, the related activities are carried out. So as to meet the needs of students ' growth and enhance their own service consciousness. Only in this way can we better arouse the enthusiasm of students, so that students can participate widely in the activities, the effect of the activities will be promoted

University Student Volunteer Service Should Make Full Use of New Media. Today's society, the Internet has entered every household. Mobile phones and computers have become an indispensable mobile device in student life. A small network is a huge influence. Voluntary service activities are not limited to the real world, but can be extended to virtual networks. They complement each other and promote voluntary service activities to be carried out better. Voluntary service organizations can use QQ, micro-blog, micro-mail and other software, widely set up an online communication platform for volunteers and the object of Help to build communication channels. It can also attract more new members by means of sweeping code. Every netizen can be the initiator, participant and supervisor of voluntary activities, so that every netizen participates in volunteering activities, and promotes the development of volunteer service. Through the spread and spread of the network, the cost of early publicity is reduced and the spreading range is increased. The use of Internet channels, to attract more social forces to participate widely in the volunteer activities of university students. Release the activities in a timely manner to make the activities more transparent and open. The use of the network can also be all over the country's volunteer service information together, to achieve national information exchange and sharing. In the shortest possible time, accurate understanding of the specific situation of the affected object, so that the right volunteers with the help of one by one faster matching, faster and more accurate service

\section{Conclusion}

In conclusion, the development of university students ' volunteering service is one of the important tasks in the higher education stage. The volunteer service of college students is a spirit of volunteerism, which has an important role in promoting the comprehensive quality of college students and promoting the development of advanced campus culture. We should standardize the work system of college students ' volunteer service, promote the all-round development of students on the one hand, and better serve the society. We should establish and perfect the working system of Voluntary service, make the correct guidance for the work of university students ' volunteer service, and impel the University Students ' voluntary service to achieve greater development results.

\section{Acknowledgement:}

"Thirteen-Five" Social Science research project of Jilin Provincial Education Department $<$ A study on the standardization of the work system of university Students ' voluntary service> No: JJKH20180720SZ

\section{References}

[1] Research on the means and form innovation of university Students ' volunteering service in "Internet +" era, Chen Zhu

[2] Research on the function of ideological and political education of university students ' volunteer service, Ge yangyang

[3] Thinking about the work of college students ' volunteering service, Wang Fangqing 
[4] Thoughts on the construction of long-lasting mechanism of university students ' voluntary service, Lan Ru

[5] On the construction of the long-term mechanism of college students ' voluntary service, Su Miao

[6] Research on the present situation and countermeasures of college students ' volunteer service under the new media environment, Huang Lin

[7] Research on college students ' volunteering service under the view of socialist core values, Zhan Liping

[8] Research on long-term mechanism of university students ' voluntary service activities, Zhang Kun

[9] Research on the status quo and development of volunteer service for minority college students, Du Juan

[10] Research on contemporary college Students ' volunteer service system, Wang Guanyu 